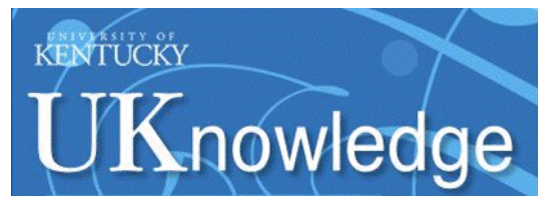

University of Kentucky

UKnowledge

Center for Applied Energy Research Faculty and Staff Publications

7-1-2017

\title{
Anion Exchange Membrane Capacitive Deionization Cells
}

Ayokunle Omosebi

University of Kentucky, ayokunle.omosebi@uky.edu

Xin Gao

University of Kentucky, xin.gao1@uky.edu

Nicolas Holubowitch

University of Kentucky, nick.holubowitch@uky.edu

Zhiao Li

University of Kentucky, lizhiao@gmail.com

James Landon

University of Kentucky, james.landon@uky.edu

See next page for additional authors

Follow this and additional works at: https://uknowledge.uky.edu/caer_facpub

Part of the Chemical Engineering Commons, Materials Science and Engineering Commons, and the Power and Energy Commons

Right click to open a feedback form in a new tab to let us know how this document benefits you.

\section{Repository Citation}

Omosebi, Ayokunle; Gao, Xin; Holubowitch, Nicolas; Li, Zhiao; Landon, James; and Liu, Kunlei, "Anion Exchange Membrane Capacitive Deionization Cells" (2017). Center for Applied Energy Research Faculty and Staff Publications. 21.

https://uknowledge.uky.edu/caer_facpub/21

This Article is brought to you for free and open access by the Center for Applied Energy Research at UKnowledge. It has been accepted for inclusion in Center for Applied Energy Research Faculty and Staff Publications by an authorized administrator of UKnowledge. For more information, please contact UKnowledge@lsv.uky.edu. 


\section{Anion Exchange Membrane Capacitive Deionization Cells}

\section{Digital Object Identifier (DOI)}

https://doi.org/10.1149/2.0461709jes

\section{Notes/Citation Information}

Published in Journal of The Electrochemical Society, v. 164, issue 9, p. E242-E247.

(c) The Author(s) 2017. Published by ECS.

This is an open access article distributed under the terms of the Creative Commons Attribution NonCommercial No Derivatives 4.0 License (CC BY-NC-ND, http://creativecommons.org/licenses/by-nc-nd/ 4.0/), which permits non-commercial reuse, distribution, and reproduction in any medium, provided the original work is not changed in any way and is properly cited. For permission for commercial reuse, please email: oa@electrochem.org.

\section{Authors}

Ayokunle Omosebi, Xin Gao, Nicolas Holubowitch, Zhiao Li, James Landon, and Kunlei Liu 


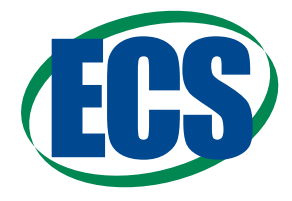

\title{
Anion Exchange Membrane Capacitive Deionization Cells
}

\author{
Ayokunle Omosebi, ${ }^{\mathrm{a}, *}$ Xin Gao, ${ }^{\mathrm{a}, *}$ Nicolas Holubowitch, ${ }^{\mathrm{a}}$ Zhiao Li, ${ }^{\mathrm{a}}$ James Landon, ${ }^{\mathrm{a}, *, \mathrm{z}}$ \\ and Kunlei Liu ${ }^{\mathbf{a}, \mathbf{b}, \mathbf{z}}$
}

${ }^{a}$ Center for Applied Energy Research, University of Kentucky, Lexington, Kentucky 40511, USA

${ }^{b}$ Department of Mechanical Engineering, University of Kentucky, Lexington, Kentucky 40506, USA

\begin{abstract}
The electrochemical response of capacitive deionization (CDI) employing a single anion exchange membrane (AEM-CDI) is contrasted to conventional two-membrane CDI (MCDI) formed with complementary anion and cation exchange membranes. Pristine activated carbon cloth electrodes that possess native positive surface charge in solution were used as both anode (positive electrode) and cathode (negative electrode) in these cells. In a separate set of tests to investigate the impact of surface charge modification on deionization responses, the single and dual membrane cells were formed with asymmetric electrodes (AEM-aCDI and aMCDI) consisting of nitric acid oxidized electrodes that possess negative surface charge as the cathode material, while pristine carbon cloth was retained as the anode material. Operating at $1.2 \mathrm{~V}$, salt adsorption capacities are $\sim 1.3,9.9$, and 16.6 , and $17.3 \mathrm{mg} \mathrm{NaCl} \mathrm{g}^{-1}$ electrode for the AEM-CDI, MCDI, AEM-aCDI, and aMCDI, respectively. The diminished performance of AEM-CDI is attributed to charge expulsion and enhanced parasitic electrochemical reactions at the unprotected cathode that reduce the charge efficiency. In contrast, for AEM-aCDI, a treated cathode enhances surface charge effects to match aMCDI performance with half the membrane requirement.

(C) The Author(s) 2017. Published by ECS. This is an open access article distributed under the terms of the Creative Commons Attribution Non-Commercial No Derivatives 4.0 License (CC BY-NC-ND, http://creativecommons.org/licenses/by-nc-nd/4.0/), which permits non-commercial reuse, distribution, and reproduction in any medium, provided the original work is not changed in any way and is properly cited. For permission for commercial reuse, please email: oa@electrochem.org. [DOI: 10.1149/2.0461709jes] All rights reserved.

(cc) BY-NC-ND
\end{abstract}

Manuscript submitted March 24, 2017; revised manuscript received May 19, 2017. Published July 1, 2017

Membrane capacitive deionization (MCDI) is an emerging water treatment technology that offers energy savings in comparison to incumbent pressure and heat driven desalination technologies when treating low to brackish level salt concentration streams. ${ }^{1}$ MCDI shares similarities with electrodialysis (ED) in that they both use complementary cation and anion selective membranes to remove dissolved ionic content with applied DC electric fields. Unlike ED, which relies on electrochemical reactions and field-driven charge diffusion facilitated by large potentials, MCDI electrostatically stores ions in electrical double-layers (EDLs) formed in highly porous electrically conductive materials, typically made of carbon (Fig. 1a). A primarily capacitive rather than charge-transfer mechanism allows the use of comparatively lower potentials with concomitant cost savings. Nonetheless, the high cost associated with membranes can still be prohibitive in terms of device commercialization. ${ }^{2}$

MCDI can operate without membranes in a process simply known as capacitive deionization (CDI). ${ }^{3-6}$ However, with membranes in place, otherwise expelled co-ions during cell polarization in CDI remain confined near the electrodes, leading to the additional flux of counter-ions from the solution bulk to neutralize the trapped unbalanced charges. ${ }^{7-9}$ The end result is a significant increase in the salt adsorption capability and energy efficiency of MCDI in comparison to conventional CDI. Once the electrodes are saturated, the system is depolarized to create a concentrated waste stream by reducing the applied potential, shorting the electrodes, or reversing the potential. In addition to suppressing ion repulsion, the membranes also mitigate faradaic currents from electroactive species and internal electronic short-circuiting that diminish cell performance.

In an effort to fabricate low cost MCDI cell stacks, charged polymers/ionomers directly cast or spray-coated onto electrodes are being examined as alternatives to commercial ion-selective membranes. ${ }^{10-12}$ These methods allow for thinner membrane layers, which translates into materials and cost savings. Although it is customary to use complementary membrane pairs in traditional MCDI cells, if a single membrane (Fig. 1b) could be used instead of a pair without sacrificing desalination performance and/or charge efficiency, then the derivative cost savings would make the technology more attractive for wide-scale commercial adoption. Previous works have already examined the performance of deionization cells configured with single cation exchange

*Electrochemical Society Member.

${ }^{\text {z} E-m a i l: ~ J a m e s . L a n d o n @ u k y . e d u ; ~ K u n l e i . L i u @ u k y . e d u ~}$ membranes showing increases in the amount of salt stored in comparison to a CDI cell, ${ }^{11,13-15}$ and we observe sorption capacity on par with MCDI (Fig. S1). Excluding a recently developed hybrid-deionization cell that combines a membrane-protected capacitive anode (positive electrode) with an intercalation-type cathode (negative electrode), ${ }^{16}$ a systematic study has not been performed for single AEM versus conventional two-membrane MCDI.

Recent experimental work has shown that the electrodes' potential of zero charge $\left(E_{\mathrm{PZC}}\right)$ significantly influences the performance of both $\mathrm{CDI}^{17-21}$ and $\mathrm{MCDI}^{22}$ cells, and amphoteric surface functional groups on carbon electrodes were used to theoretically explain the transient response of CDI cells. ${ }^{23}$ The $E_{\mathrm{PZC}}$ captures the capability of charged chemical species on the electrode's surface to attract counter ions and molecules, ${ }^{24}$ and in this work we perform $E_{\mathrm{PZC}}$ measurements to examine the response of deionization cells with surface-treated electrodes and ion exchange membranes. Moreover, electrochemical reactions can severely inhibit CDI performance, ${ }^{25-30}$ and measurement of electrochemically active dissolved oxygen (DO) and electrical charge analysis reveal their impact on the four cell configurations studied here. Since materials cost is one of the most significant barriers to widespread adoption of membrane-assisted CDI, we contrast the performance of single anion exchange membrane CDI to MCDI toward deploying a reduced cost and high performing alternative.

\section{Experimental}

Materials.-Spectracarb 2225 Type 900 activated carbon fabric (Engineered Fibers Technology, LLC) was used as the microporous electrode material in this work. The as-received Spectracarb (SC) electrodes were designated as pristine (SC-Pr). For electrode treatment, pristine SC electrodes were first soaked in $65 \mathrm{wt} \% \mathrm{HNO}_{3}$ for 24 hours, then subsequently heated in DI water at $80^{\circ} \mathrm{C}$ for $1-2$ hours, followed by repeated rinsing in copious amounts of DI water. The treated electrodes, designated as SC-Ox, were dried in a convection oven maintained at $80^{\circ} \mathrm{C}$ and subsequently stored under vacuum until required for testing or characterization. For configuring the deionization cells, Neosepta AMX and CMX membranes were respectively used as anion and cation exchange membranes in this work.

Pore and surface characterization.-Pore characteristics of the SC electrodes were examined with a Micromeritics ASAP 2020 porosimetry analyzer. Test samples were first evacuated and degassed 

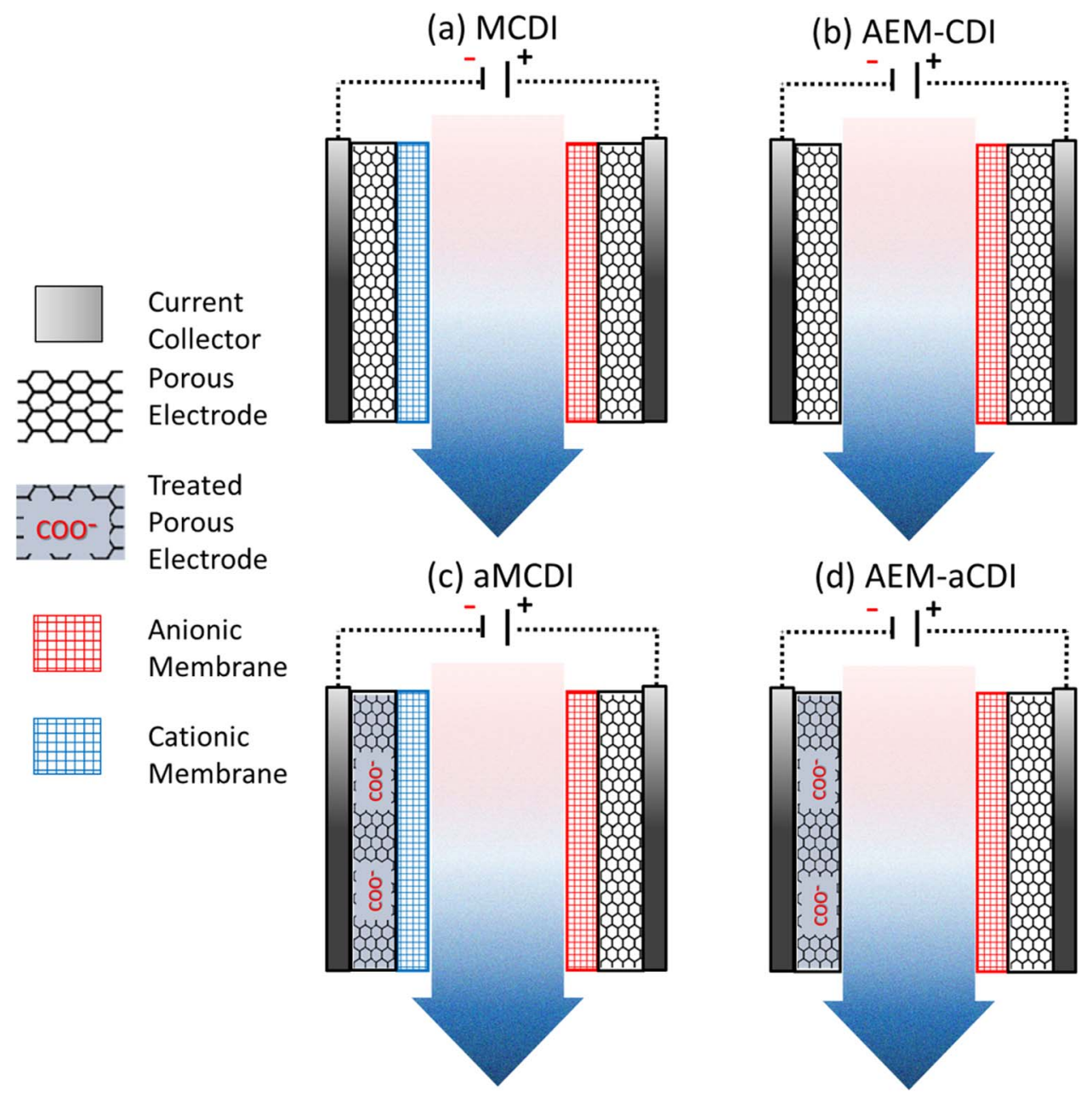

Figure 1. Schematic of MCDI (a), AEM-CDI (b), aMCDI (c), and AEM-aCDI (d). MCDI and AEM-CDI are formed with pristine activated carbon cloth electrodes as both anode (positive electrode) and cathode (negative electrode). aMCDI and AEM-aCDI are formed with nitric acid treated carbon cloth as cathode, while pristine carbon cloth is retained as anode.

at $160^{\circ} \mathrm{C}$ for 240 minutes, followed by $\mathrm{N}_{2}$ adsorption/desorption at 77 $\mathrm{K}$ to assess pore configurations. A Fourier-transform infrared (FTIR) spectrometer (Nicolet 6700, Thermo Scientific) was used to characterize the surface species of the SC-Pr and SC-Ox electrodes. FTIR samples were prepared with around $0.07 \mathrm{~g}$ of a mixture of carbon $/ \mathrm{KBr}$ at a ratio of $0.3 \mathrm{wt} \%$ (SC vs. $\mathrm{KBr}$ ), and FTIR spectra were collected by co-adding 256 scans at $4 \mathrm{~cm}^{-1}$ resolution.

Electrochemical characterization.- $-E_{\mathrm{PZC}}$ information was obtained from single frequency differential capacitance electrochemical impedance spectroscopy (EIS) measurements using a Gamry Reference 600 potentiostat/galvanostat. In a typical experiment, SC was configured as the working electrode using the assembly shown in Fig. $\mathrm{S} 2$, while a rolled $75 \mathrm{~cm} \times 15 \mathrm{~cm}$ titanium mesh (Dexmet) was the counter electrode. Testing was done in a three-electrode half-cell setup with a saturated calomel reference electrode (SCE, $E^{0}=0.244 \mathrm{~V}$ vs. $\mathrm{SHE}$ at $25^{\circ} \mathrm{C}$ ) and deaerated $5 \mathrm{mM} \mathrm{NaCl}$ solution as the electrolyte. The solution exposed geometric area of the working electrode was $\sim 0.3 \mathrm{~cm}^{2}$. EIS data were obtained by inputting a $5 \mathrm{mV}$ RMS amplitude signal at a single frequency of $1.5 \mathrm{mHz}$ at potentials from -0.4 to $0.8 \mathrm{~V}$ vs. SCE with increments of $0.1 \mathrm{~V}$. The potentials were scanned in the anodic direction to ameliorate electrochemical oxidation effects on subsequent data, since up to four cycles are performed by the potentiostat before logging a data point. For membrane-electrode configurations, the test membrane was clamped on either side of the SC electrode as shown in Fig. S2. The capacitance was derived from the imaginary part of the impedance spectrum $\left(Z^{\prime \prime}\right)$ and angular frequency $(\omega)$ according to the following equation:

$$
C=\left|1 / \omega Z^{\prime \prime}\right|
$$

where the $E_{\mathrm{PZC}}$ is the potential at the minima of the differential capacitance (i.e., capacitance vs. potential) plot. ${ }^{31}$

Deionization performance setup.-Deionization experiments were carried out in batch mode where $1 \mathrm{~L}$ of $5 \mathrm{mM} \mathrm{NaCl}$ solution contained in a reservoir was recirculated at $25 \mathrm{~mL} \mathrm{~min}^{-1}$ through a deionization cell using a peristaltic pump (Cole-Parmer Masterflex $\mathrm{L} / \mathrm{S}$ ). In-line concentration and dissolved oxygen probes connected to the exit of the deionization cell were used to monitor effluent properties. A power supply (Circuit Specialists 3644 A) was used to apply potential to the cell, while the current was measured. A Graphtec midi logger GL220 was programmed to log data of all signals at a rate of $0.2 \mathrm{~Hz}$. The reservoir was continuously purged with argon gas during cell testing to achieve a dissolved oxygen content of $\sim 3 \mathrm{ppm}$. An Allen Bradley programmable logic controller (Micrologix 100) was used to cycle the test cell between $1.2 \mathrm{~V}$ (charging) and short-circuit (discharging) for a total of 50 hours with each charge and discharge step lasting one hour ( 25 cycles). The flow-by MCDI deionization cell was constructed from a sequential stack of current collector (graphite), positive electrode (anode, SC-Pr), anion exchange membrane (AEM), spacer, cation exchange membrane (CEM), negative electrode (cathode, SC-Pr), and current collector. The test solution flowed between 
the membranes, which were separated by a $\sim 2 \mathrm{~mm}$ thick channel composed of a rubber gasket, filter paper, and additional rubber gasket sandwich assembly. Single anion exchange membrane CDI cells with pristine electrodes (AEM-CDI) were similarly configured albeit with a membrane (AEM) only at the anode. Oxidized (treated) electrodes were configured as cathodes whenever used, and dual membrane and single anion exchange membrane asymmetric electrode cells with SCPr anode and SC-Ox cathode are denoted as aMCDI and AEM-aCDI, respectively. A total of $\sim 1.4 \mathrm{~g}$ of electrodes with $8.8 \mathrm{~cm} \times 5 \mathrm{~cm}$ geometric area was used for each cell, and all test cells were tightened with a torque of $4 \mathrm{~N}-\mathrm{m}$ to ensure consistent cell compression. All electrodes were pre-wetted with the test solution before cell assembly, and the salt solution was circulated through the assembled system for 12-24 hours in short-circuit mode prior to experiments. Salt adsorption capacity, SAC, of the carbon was determined from the concentration drop of the salt solution converted to mass, normalized by the total mass of electrodes using Equation 2:

$$
\mathrm{SAC}=V[\Delta C] m^{-1}
$$

where $\Delta \mathrm{C}$ is the steady state concentration difference $\left(\mathrm{mg} \mathrm{L}^{-1}\right)$ between the adsorption and desorption steps calculated from the last 200 s of each step. $V$ and $m$ are the volume of the salt solution (L) and mass of the electrodes $(\mathrm{g})$, respectively. The desalination charge efficiency $(\Lambda)$ is the ratio of ionic charge to the cumulative electronic charge passed during the adsorption step, $Q$, calculated from the integral of the current profile during the adsorption step (Equation 3).

$$
\Lambda=F V[\Delta C]\left[M_{w} Q\right]^{-1}
$$

where $\mathrm{F}$ and $M_{\mathrm{w}}$ are Faraday's constant and molecular weight of $\mathrm{NaCl}$ $\left(58.44 \mathrm{~g} \mathrm{~mol}^{-1}\right)$, respectively.

A similar cell structure with a larger, $\sim 6 \mathrm{~mm}$ spacer channel was also assembled to accommodate a $\mathrm{Ag} / \mathrm{AgCl}$ reference electrode for measuring the electrodes' potential distribution in operando, and a schematic of this cell is provided in Fig. S3. This cell enables the measurement of the anode and cathode charging potentials $E^{+}$and $E^{-}$, and their respective potential at discharge $E_{0}$ relative to the $\mathrm{Ag} / \mathrm{AgCl}$ reference electrode $\left(E^{0}=0.199 \mathrm{~V}\right.$ vs. SHE at $\left.25^{\circ} \mathrm{C}\right)$.

\section{Results and Discussion}

Surface and interfacial properties.-Applying a potential to an ideally polarizable electrode, i.e., an interface across which faradaic charge transfer cannot occur, in a dilute salt solution results in the adsorption/desorption of counter- or co-ions depending on deviation from the electrode's $E_{\mathrm{PZC}}$, the potential for which there is no net charge in the EDL. The $E_{\mathrm{PZC}}$ depends on surface functional and specifically adsorbed chemical groups on the electrode and can be identified as a minimum in capacitance versus potential plots (qualitatively represented in Fig. 2a). ${ }^{32-34}$ For an electrode with charged surface groups, charge balance is achieved via:

$$
\sigma_{\text {chem }}^{+}+\sigma_{\text {chem }}^{-}+\sigma_{\text {ion }}^{+}+\sigma_{\text {ion }}^{-}+\sigma_{\mathrm{e}}=0
$$

where $\sigma_{\text {chem }}^{+}, \sigma_{\text {chem }}^{-}, \sigma_{\text {ion }}^{+}, \sigma_{\text {ion }}^{-}$, and $\sigma_{\mathrm{e}}$ are the positive and negative surface chemical and ionic charges, and electronic charge. Note that $\sigma_{\text {chem }}^{+}, \sigma_{\text {ion }}^{+}>0$, while $\sigma_{\text {chem }}^{-}, \sigma_{\text {ion }}^{-}<0$. Defining the electrode to include functionalized and non-functionalized parts, then according to Bard and Faulkner, ${ }^{35} \sigma_{\text {chem }}^{+}+\sigma_{\text {chem }}^{-}+\sigma_{\mathrm{e}}=0$ at $E_{\text {PZC. }}$. It then follows that for an arbitrary surface (e.g., surface 1) predominantly composed of positive surface chemical charges (i.e., $\sigma_{\text {chem }}^{+} \gg-\sigma_{\text {chem }}^{-}$), $\sigma_{\text {e, surface } 1}$ is less than zero to balance $\sigma_{\text {chem }}^{+}$for neutrality. Likewise for a surface (e.g., surface 2) with a preponderance of negative chemical charge (i.e., $\sigma_{\text {chem }}^{+} \ll-\sigma_{\text {chem }}^{-}$), $\sigma_{\text {e, surface } 2}$ will be greater than zero to balance $\sigma_{\text {chem }}^{-}$. Assuming potential and charge follow the normal convention such that $\sigma_{e}<0$, when $\mathrm{E}<0$, and likewise $\sigma_{\mathrm{e}}>0$ when $\mathrm{E}>0$, which establishes that $\sigma_{\mathrm{e} \text {,surface } 2}-\sigma_{\mathrm{e} \text {,surface } 1}>0$ and correspondingly, $E_{\mathrm{PZC} \text {, surface 2 }}>E_{\mathrm{PZC} \text {, surface 1. It then follows that a switch in the charge }}$ polarity of surface chemical groups on an electrode results in the relative relocation of the potential of zero charge according to the
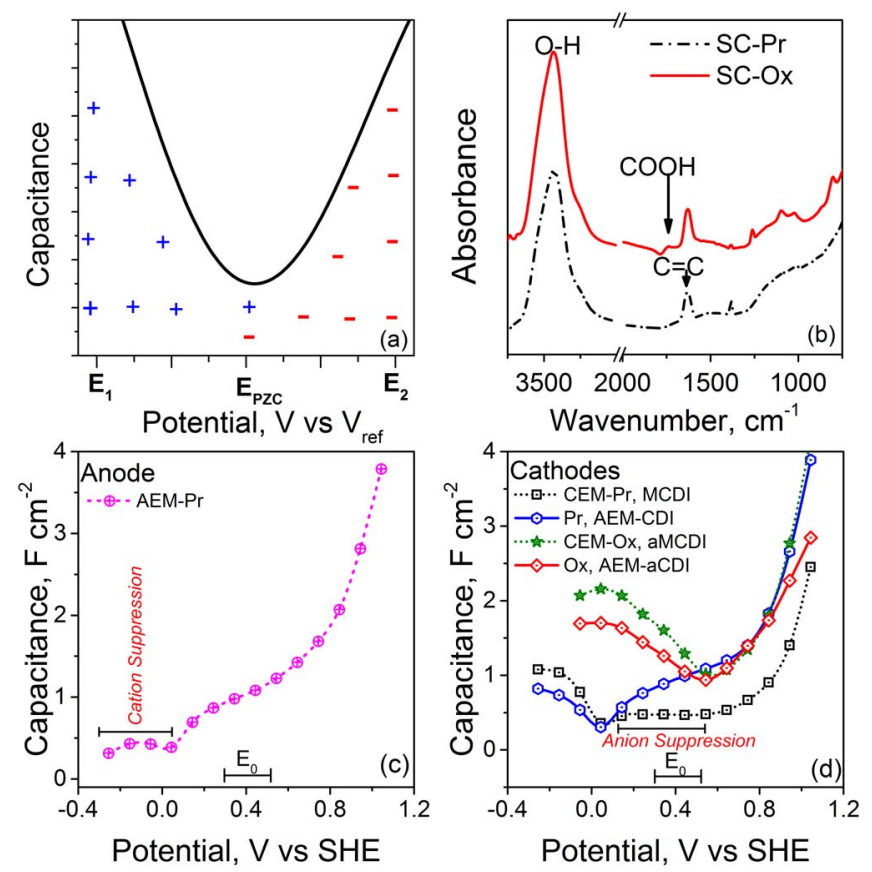

Figure 2. Qualitative representation of charge attracted to an electrode at deviations from the potential of zero charge $\left(E_{\mathrm{PZC}}\right)(\mathrm{a})$, FTIR spectra of pristine (SC-Pr) and oxidized (SC-Ox) Spectracarb electrodes (b), EIS differential capacitance plot for the electrode and electrode-membrane combinations for the anode (c), and cathode (d) used to form the test cells. Capacitance experiments were conducted with a $5 \mathrm{mM} \mathrm{NaCl}$ solution. $\mathrm{E}_{0}$ was measured with the potential distribution apparatus described in Fig. S3.

following equations.

$$
\sigma_{\mathrm{e}}\left(\sigma_{\text {chem }}^{+}\right)<\sigma_{\mathrm{e}}\left(\sigma_{\text {chem }}^{-}\right)
$$

$$
E_{\mathrm{PZC}}\left(\sigma_{\text {chem }}^{+}\right)<E_{\mathrm{PZC}}\left(\sigma_{\text {chem }}^{-}\right)
$$

We consider that for an electrode, at applied potentials positive to the $E_{\mathrm{PZC}}$, the EDL possesses an excess of anions $\left(\mathrm{E}_{2}\right)$, while there is an excess of cations at applied potentials negative of the $E_{\mathrm{PZC}}\left(\mathrm{E}_{1}\right)$ (Fig. 2a). Also by extension, a more positive $E_{\text {PZC }}$ favors cation adsorption and vice-versa for a more negative $E_{\mathrm{PZC}}$. FTIR analyses of $\mathrm{SC}-\mathrm{Pr}$ and SC-Ox (Fig. 2b) shows characteristic $\mathrm{C}=\mathrm{C}$ vibrations $(1630$ $\left.\mathrm{cm}^{-1}\right)$ for both electrodes, as well as -OH $\left(3430 \mathrm{~cm}^{-1}\right)$ surface groups that can be protonated to yield $\sigma_{\text {chem }}^{+}$via ionization with water. ${ }^{36-38}$ $\sigma_{\text {chem }}^{+}$may also arise within the carbon basal planes to attract anions from solution. ${ }^{39}$ In addition, the SC-Ox electrodes show carboxylic acid functionalities at a wavenumber of $1730 \mathrm{~cm}^{-1}$ that can be deprotonated to become negatively charged $\left(\sigma_{\text {chem }}^{-}\right)$and attract cations from solution. $E_{\mathrm{PZC}}$ shifting to more positive potentials is therefore expected as more $\mathrm{COO}^{-}\left(\sigma_{\text {chem }}^{-}\right)$is created on a $\mathrm{SC}$ electrode from converting SC-Pr to SC-Ox.

Differential capacitance, the change in capacitance with applied potential, was measured with and without ion exchange membranes on each electrode to assess their $E_{\mathrm{PZC}}$ 's. Fig. 2c shows the EIS differential capacitance plot for the SC-Pr and AEM combination used as anode for all the test cells. This membrane-assisted electrode shows cation capacitance suppression from -0.24 to $0.04 \mathrm{~V}$ vs. SHE due to the influence of the AEM, then potential dependent capacitance response consistent with charge storage in the diffuse layer of the EDL in low concentration solutions. For the cathodes (Fig. 2d), it can be summarized that (i) the CEM membrane did not shift the $5 \mathrm{mM}$ $\mathrm{NaCl}$ pre-wetted carbon-electrodes $E_{\text {PZC }}$ (also pertinent to the AEM in Fig. 2c), (ii) anion capacitance suppression is evident in the CEM-Pr combination from 0.04 to $0.54 \mathrm{~V}$ vs. SHE due to the influence of the $\mathrm{CEM}$, followed by a capacitive response from anion leakage through 

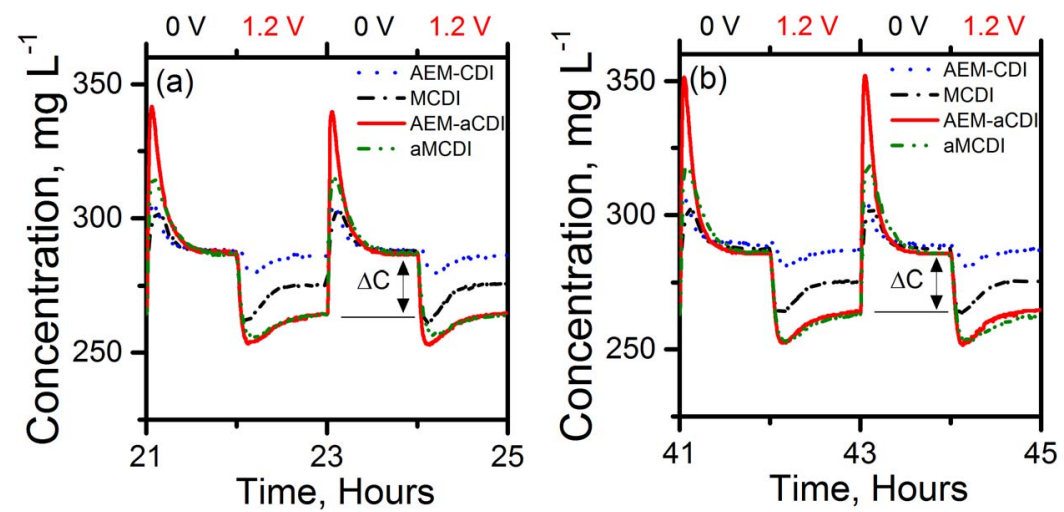

Figure 3. Concentration profiles for the $21^{\text {st }}$ to $25^{\text {th }}$ (a) and $41^{\text {st }}$ to $45^{\text {th }}$ (b) hours of operation for the AEM-CDI, MCDI, AEMaCDI, and aMCDI cells. Performance testing was conducted by polarizing $(1.2 \mathrm{~V})$ and depolarizing (short-circuit) a $1 \mathrm{~L}$ volume of a $\sim 5 \mathrm{mM} \mathrm{NaCl}$ stream recirculating at $25 \mathrm{ml} \mathrm{min}^{-1}$ in the test cell.

the cationic membrane or faradaic response from carbon oxidation, (iii) there is no suppression in the Ox-CEM combination on account of the incidence of the $E_{\mathrm{PZC}}$ with the tail-end of the anion suppression domain at $0.54 \mathrm{~V}$ vs. SHE, and (iv) the oxidized cathodes (Ox and Ox-CEM) favor more cation adsorption in accordance with Eq. 5. The corresponding $E_{\mathrm{PZC}}$ 's for the SC-Pr and SC-Ox electrodes are 0.04 and $0.54 \mathrm{~V}$ vs. SHE, respectively, and the cyclic voltammograms for all the tested electrode/electrode-membrane combinations are shown Fig. S4.

Cycling performance of dual and single membrane CDI cells.Experimental deionization testing consists of alternating charge and discharge steps where in batch mode operation the steady-state concentration difference $(\Delta C)$ between these steps indicates the amount of ions stored within the EDL. Fig. 3a shows a snapshot of deionization data for the single membrane (AEM-CDI, AEM-aCDI) and dual membrane (MCDI, aMCDI) cells at 21-25 hours of operation. Cells with symmetric pristine electrodes show the lowest concentration differences of $2.1 \mathrm{mg} \mathrm{L}^{-1}$ for AEM-CDI and $13.2 \mathrm{mg} \mathrm{L}^{-1}$ for MCDI. In contrast, cells with oxidized cathodes (AEM-aCDI and aMCDI), both showed improved performances $>20 \mathrm{mg} \mathrm{L}^{-1}$. This increase cannot be explained by porosimetry data, since electrode oxidation does not increase pore volume (Fig. S5), but relocates the $E_{\mathrm{PZC}}$ (Figure 2d, Eq. 5). Based on the surface charge and $E_{\mathrm{PZC}}$ of the AEM-CDI anode and cathode, both electrodes will natively attract anions at the short circuit potential, $\mathrm{E}_{0}$, and anion repulsion to the bulk is therefore required at the cathode before cation adsorption can occur upon charging. Measured $\mathrm{E}_{0}$ was $0.51,0.43,0.46$, and $0.30 \mathrm{~V}$ vs. SHE for AEM-CDI, MCDI, AEM-aCDI, and aMCDI, respectively. In contrast, this repulsion effect is muted by the cation exchange membrane in MCDI (Fig. 2d, anion suppression region). For asymmetric cells, the oxidized cathodes (i) natively adsorb cations at $\mathrm{E}_{0}$, avoiding the repulsion process and (ii) show a larger capacitance for cation stor- age at potentials less than $\mathrm{E}_{0}$ (Fig. 2d), explaining their greater salt adsorption. In addition, their similarity in $E_{\mathrm{PZC}}$ and capacitance levels in Fig. 2d, further suggests similarities in performance as observed in Fig. 3. The larger concentration drop observed for the AEM-aCDI and aMCDI cells is consistent with previous observations from CDI cells formed with pristine and oxidized electrode combinations (without membranes). ${ }^{19,22}$ Similar performance is maintained at 41 to 45 hours operation (Fig. 3b), and concentration cycling data for the entire 50-hour test period for the test cells are shown in Fig. S6(a).

Electrochemical reactions and dissolved oxygen in MCDI and single membrane CDI.-Beyond their ability to facilitate selective ion permeation, membranes restrict electrochemically active DO from accessing the electrodes (Fig. S7). Similar observations are reported for Nafion and Neosepta ACH-45T membranes. ${ }^{40}$ DO accessing the cell electrodes can provide a route for parasitic, irreversible charge consumption during deionization, reducing the efficacy of the desalination process. All carbon materials are noted to show some electrocatalytic activity toward the oxygen reduction reaction (ORR) in alkaline solution, via the 2 or 4 electron reaction pathway, ${ }^{41}$ and the redox potential $\mathrm{E}^{0}$ for the relevant reactions in basic media are: ${ }^{42}$

$$
\mathrm{O}_{2}+2 \mathrm{H}_{2} \mathrm{O}+2 \mathrm{e}^{-} \rightleftarrows \mathrm{H}_{2} \mathrm{O}_{2}+2 \mathrm{OH}^{-} \quad E^{0}=-0.15 \mathrm{~V} v s \text {. SHE }
$$

$$
\mathrm{O}_{2}+2 \mathrm{H}_{2} \mathrm{O}+4 \mathrm{e}^{-} \rightleftarrows 4 \mathrm{OH}^{-} \quad E^{0}=0.40 \mathrm{~V} v \text { s. SHE }
$$

Based on the potential distribution of AEM-CDI, MCDI, AEM-aCDI, and aMCDI cells, all of the test cells show some favorability toward cathodic ORR (Figs. 4a-4d) during $1.2 \mathrm{~V}$ charging as $E^{0}>E^{-}$. It should be noted that reduction via Eq. 6 and 7 would be exacerbated under acidic conditions given their higher $E^{0}$. However, the cation exchange membrane functionally screens DO from the cathode as evident from the effluent DO responses in Figs. 5a-5b. The single
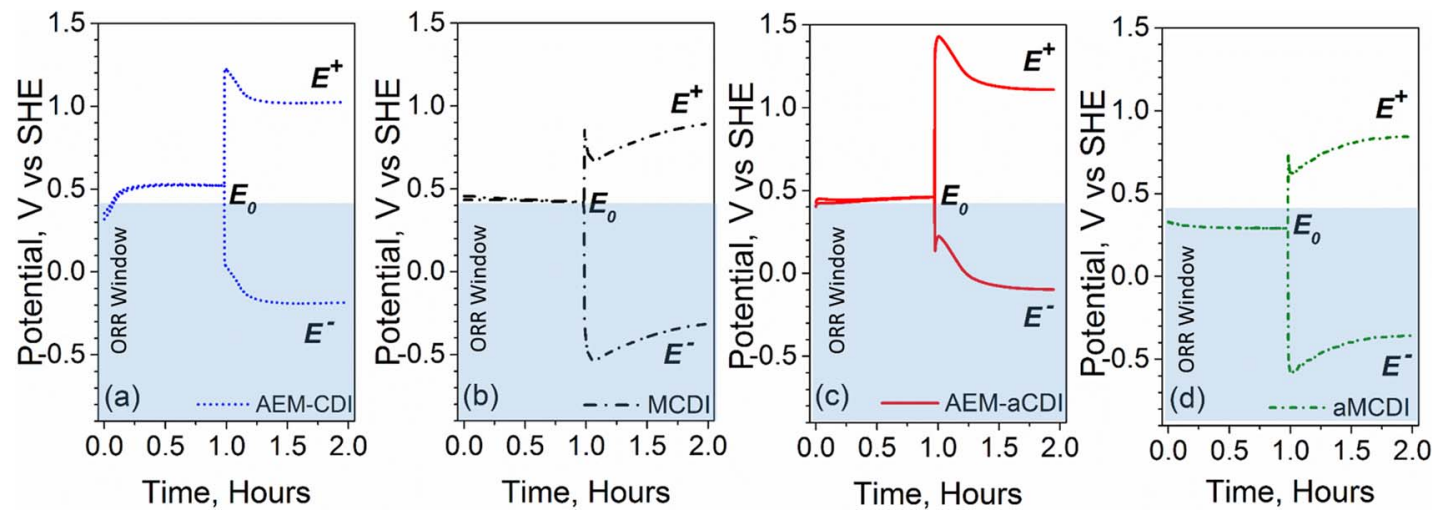

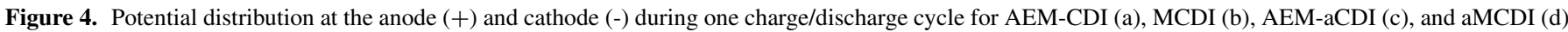
test cells. Potential distributions were measured with the apparatus described in Fig. S3. 

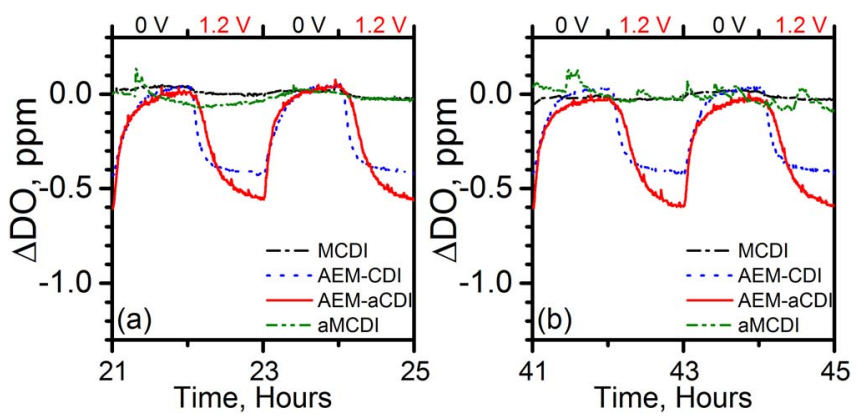

Figure 5. Profiles for dissolved oxygen (DO) during the $21^{\text {st }}$ to $25^{\text {th }}$ (a) and $41^{\text {st }}$ to $45^{\text {th }}$ (b) hours of operation for the AEM-CDI, MCDI, AEM-aCDI, and aMCDI cells. Testing was conducted by cyclically polarizing $(1.2 \mathrm{~V})$ and depolarizing (short-circuit) a cell with a recirculating $1 \mathrm{~L}$ volume of a $5 \mathrm{mM}$ $\mathrm{NaCl}$ solution.

anion exchange membrane cells show a steady state perturbation, $\Delta_{\text {DO }}$, of -0.4 to $-0.6 \mathrm{ppm}$, whereas the dual membrane cells show negligible DO perturbation. During discharge (cell voltage $=0 \mathrm{~V}$ ), the DO concentration returns to its equilibrium value dictated by the purge rate of the inert gas and dissolution of atmospheric oxygen back into the solution reservoir. These DO profile trends are still maintained during the $41^{\text {st }}$ to $45^{\text {th }}$ hours of operation (Fig. 5b), and since it is unlikely that purely capacitive processes affect uncharged dissolved oxygen, the DO response is considered entirely faradaic in nature and suppressed when a membrane protects the cathode.

In comparing potential distributions (Figs. 4a-4d), we consider that the facility of the ORR reaction at the cathode can reduce the cathode faradaic resistance causing a redistribution of system potentials. However, it is also plausible that removing the cation exchange membrane (CEM) from the MCDI or aMCDI cathode results in an anodic shift of the working potential window. This is likely accounted for by repartitioning of the resistances in the deionization cell when considering its equivalent circuit diagram (Fig. S8). The total resistance for the system is therefore a summation of anodic and cathodic charge transfer resistances, electronic resistance (within the electrodes, current collectors, and electrical wiring plus their contact resistances), and ionic resistances (solution, plus anion and cation membranes). Removing the CEM hence reduces the cathode resistance to current, and correspondingly increases the potential drop (overpotential due to a now larger relative resistance) at the anode explaining the $\sim 0.3 \mathrm{~V}$ positive shift in the potential window. A treatment of ionic and electronic resistances in MCDI can be found in Ref. 43.

Efficiency and membrane-normalized performance.-Eliminating a membrane from an MCDI process is an attractive option if performance is retained or improved. Key performance metrics including salt adsorption capacity (SAC), cumulative charge input, and efficiency for the AEM-CDI, MCDI, AEM-aCDI, and aMCDI cells during the 50 hour ( 25 cycle) test period are shown in Figs. 6a-6c. Their nominal SACs' are 1.3, 9.9, and 16.6 , and $17.3 \mathrm{mg} \mathrm{NaCl} \mathrm{g}^{-1}$ for nominal electronic charge inputs of $21.8,18.2,33.4$, and $26.9 \mathrm{C}$ $\mathrm{g}^{-1}$, corresponding to charge efficiencies of $0.1,0.9,0.8$ and unity. As expected, the dual membrane cells showed higher efficiency over their single membrane counterparts, consistent with their ability to mitigate parasitic charge consumption from electrochemical DO reactions. Moreover, Figs. $6 \mathrm{a}-6 \mathrm{c}$ shows that these profiles are stable during the entirety of the test period indicating the capability of both the dual membrane and single AEM membrane for performance preservation.

In considering Fig. 6a, it appears there is a greater benefit from having the appropriate $E_{\mathrm{PZC}}$ 's $/ \sigma_{\text {chem }}$ (AEM-aCDI, aMCDI) than from ion suppression (MCDI). This is supported by the increase in charge passed with the asymmetric electrode cells (AEM-aCDI, aMCDI), corresponding to more ions adsorbed and with minimal loss of efficiency from faradaic processes. The low performance of AEM-CDI is in part explained by the exacerbated changes in $\mathrm{pH}$ (Fig. S9) due to the
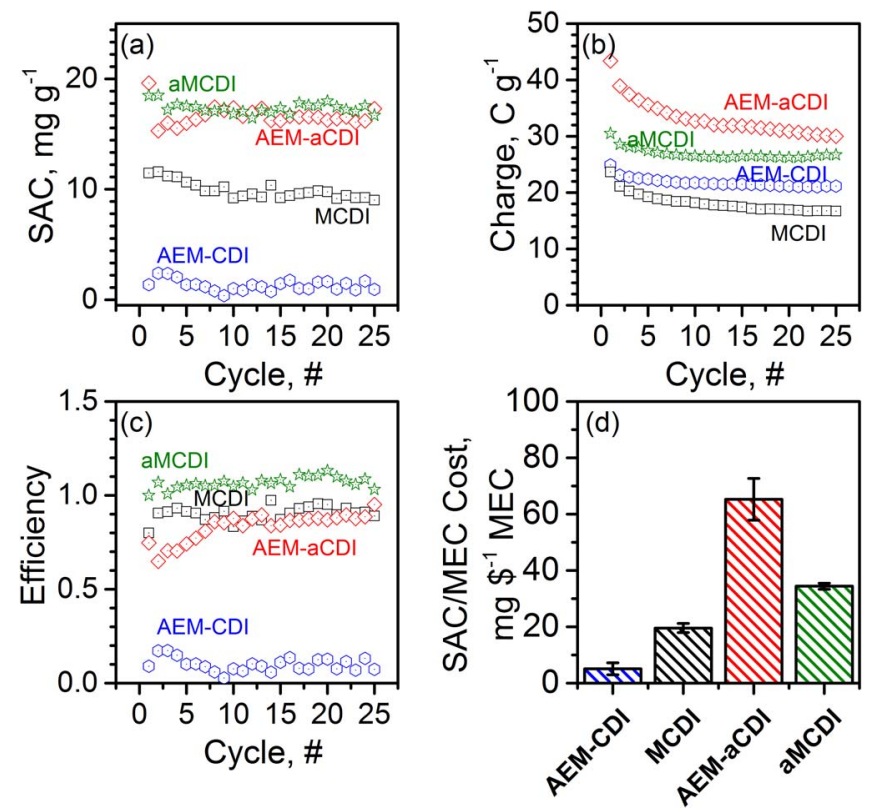

Figure 6. Cycle to cycle salt adsorption capacity (a), input electronic charge (b), efficiency (c), and the projected average salt adsorption per cost of membrane electrode component (MEC) used (d) for the AEM-CDI, MCDI, AEM$\mathrm{aCDI}$, and aMCDI test cells during 50 hours of continuous performance cycling of a $1 \mathrm{~L}$ volume of a $5 \mathrm{mM} \mathrm{NaCl}$ stream recirculating at $25 \mathrm{ml} \mathrm{min}^{-1}$. Error bars indicate the standard deviation.

secondary effect of the ORR creating conductivity interfering $\mathrm{OH}^{-}$ ions that counteract the deionization operation. It is noteworthy that previous works on CDI employing asymmetric surface charge modified electrodes also report improved SAC relative to cells formed with symmetric electrodes..$^{20,21,44}$ However, from the 50 hour data in Fig S10e, the single membrane cells show more stable SACs over their membrane-free counterparts. Nonetheless, longer-term testing of the single membrane cells will be required to further demonstrate their ultimate viability.

Since the addition of the membrane increases the cost of the device, the relative cost of desalination for the cells studied here can be approximated by normalizing salt adsorption by the cost of the membrane electrode component (MEC) (Fig. 5d). The MEC cost is the estimated total materials cost for all electrodes and membranes used to form a cell. Currently, there is intensive research into new materials for MCDI cells, but an eventual balance must be made between materials cost and realized performance benefits. Carbon electrodes can cost between US\$ $4-50 \mathrm{~kg}^{-1}$ depending on purity and sophistication, ${ }^{45}$ while ion exchange membrane prices as low as US $\$ 80 \mathrm{~m}^{-2}$ have been reported. ${ }^{2}$ The lower electrode and membrane prices are adopted for the data presented in Fig. $6 \mathrm{~d}$ using $1.4 \mathrm{~g}$ of electrodes and $44 \mathrm{~cm}^{2}$ geometric area per membrane. The corresponding salt adsorbed per MEC used were 5.1, 19.6, 65.3, and $34.4 \mathrm{mg} \mathrm{NaCl-US \$}{ }^{-1}$ for AEMCDI, MCDI, AEM-aCDI, and aMCDI, respectively. Compared to the MCDI and aMCDI cells, the AEM-aCDI cell shows a respective 3.4 and 2.0 times increase for salt adsorbed per price of MEC assembly and is only fractionally less efficient, making it attractive for CDI commercialization.

\section{Conclusions}

We presented deionization performance results for the operation of conventional dual membrane and single anion exchange membrane capacitive deionization cells. These cells were operated at $1.2 \mathrm{~V}$, and SACs for cells with all-pristine symmetric electrodes were 1.3 and $9.9 \mathrm{mg} \mathrm{g}^{-1}$ for the one and two-membrane cells, respectively. Poor performance for the AEM-CDI cell was attributed to ionic charge 
expulsion at the cathode due to its $E_{\mathrm{PZC}}$ location /surface charge effects and parasitic charge consumption. A modified cell, AEM-aCDI, formed with a single anion exchange membrane and asymmetric electrodes consisting of a pristine anode and oxidized cathode resulted in a high nominal SAC of $16.6 \mathrm{mg} \mathrm{g}^{-1}$ at nearly half the MEC cost (without other associated system costs) of MCDI/aMCDI cells. The asymmetric configuration was found to boost performance due to their increased cathodic capacitance and favorable $E_{\mathrm{PZC}}$ locations, which minimizes ionic charge expulsion. The negative surface charge introduced via chemical oxidation pre-treatment increases the cation capacity of the cathode.

Finally, this work demonstrated a new route to achieving cost savings while maintaining or improving performance in a membraneassisted CDI system, showing only a single membrane is necessary for high-performance CDI. Further tailoring electrode $E_{\mathrm{PZC}}$ 's (e.g. reducing the positive electrode's or increasing the negative electrode's $\left.E_{\mathrm{PZC}}\right)$ may lead to even greater salt adsorption capacity and efficiency in single-membrane cells.

\section{Acknowledgments}

The authors are grateful to the U.S.-China Clean Energy Research Center, U.S. Department of Energy for project funding (No. DE-PI0000017). The authors also thank Mr. R. Perrone for help in designing and constructing the MCDI cells.

\section{References}

1. R. Zhao, S. Porada, P. M. Biesheuvel, and A. van der Wal, Desalination, 330, 35 (2013).

2. L. Weinstein and R. Dash, Desalin. Water Reuse, 23, 34 (2013).

3. J. J. Lado, R. E. Pérez-Roa, J. J. Wouters, M. I. Tejedor-Tejedor, C. Federspill, and M. A. Anderson, Journal of Environmental Chemical Engineering, 3, 2358 (2015).

4. K. Laxman, L. A. Gharibi, and J. Dutta, Electrochim. Acta, 176, 420 (2015).

5. J. C. Farmer, D. V. Fix, G. V. Mack, R. W. Pekala, and J. F. Poco, J. Electrochem Soc., 143, 159 (1996)

6. M. A. Anderson, A. L. Cudero, and J. Palma, Electrochim. Acta, 55, 3845 (2010).

7. P. M. Biesheuvel and A. van der Wal, J. Membr. Sci., 346, 256 (2010).

8. M. E. Suss, S. Porada, X. Sun, P. M. Biesheuvel, J. Yoon, and V. Presser, Energy Environ. Sci., 8, 2296 (2015).

9. H. Li and L. Zou, Desalination, 275, 62 (2011).

10. J.-Y. Lee, S.-J. Seo, S.-H. Yun, and S.-H. Moon, Water Res., 45, 5375 (2011)

11. Y.-J. Kim and J.-H. Choi, Water Res., 44, 990 (2010).

12. X. Gao, A. Omosebi, N. Holubowitch, A. Liu, K. Ruh, J. Landon, and K. Liu, Desalination, 399, 16 (2016).

13. C. Nie, L. Pan, Y. Liu, H. Li, T. Chen, T. Lu, and Z. Sun, Electrochim. Acta, 66, 106 (2012).

14. S. Porada, B. B. Sales, H. V. M. Hamelers, and P. M. Biesheuvel, The Journal of Physical Chemistry Letters, 3, 1613 (2012).
15. H. Yoon, J. Lee, S.-R. Kim, J. Kang, S. Kim, C. Kim, and J. Yoon, Desalination, 392 $46(2016)$

16. J. Lee, S. Kim, C. Kim, and J. Yoon, Energy \& Environmental Science, 7, 3683 (2014).

17. E. Avraham, M. Noked, I. Cohen, A. Soffer, and D. Aurbach, J. Electrochem. Soc., 158, P168 (2011).

18. I. Cohen, E. Avraham, M. Noked, A. Soffer, and D. Aurbach, The Journal of Physical Chemistry C, 115, 19856 (2011).

19. X. Gao, A. Omosebi, J. Landon, and K. Liu, Electrochem. Commun., 39, 22 (2014).

20. T. Wu, G. Wang, Q. Dong, B. Qian, Y. Meng, and J. Qiu, Electrochim. Acta, 176, 426 (2015).

21. B. Qian, G. Wang, Z. Ling, Q. Dong, T. Wu, X. Zhang, and J. Qiu, Advanced Materials Interfaces, 2 (2015).

22. A. Omosebi, X. Gao, J. Rentschler, J. Landon, and K. Liu, J. Colloid Interface Sci., 446, 345 (2015).

23. P. M. Biesheuvel, H. V. M. Hamelers, and M. E. Suss, Colloids and Interface Science Communications, 9, 1 (2015).

24. P. Horsman, B. E. Conway, and E. Yeager, Comprehensive Treatise of Electrochemistry: The Double Layer, Springer US (1980).

25. D. He, C. E. Wong, W. Tang, P. Kovalsky, and T. D. Waite, Environmental Science \& Technology Letters, 3, 222 (2016).

26. J.-H. Choi, Desalination, 347, 224 (2014).

27. Y. Bouhadana, M. Ben-Tzion, A. Soffer, and D. Aurbach, Desalination, 268, 253 (2011).

28. A. G. El-Deen, J.-H. Choi, C. S. Kim, K. A. Khalil, A. A. Almajid, and N. A. M. Barakat, Desalination, 361, 53 (2015).

29. S. Shanbhag, J. Whitacre, and M. Mauter, J. Electrochem. Soc., 163, E363 (2016).

30. B. Shapira, E. Avraham, and D. Aurbach, Electrochim. Acta, 220, 285 (2016).

31. A. Omosebi, X. Gao, J. Landon, and K. Liu, ACS Applied Materials \& Interfaces, 6 , 12640 (2014)

32. J. M. Bockris, S. Argade, and E. Gileadi, Electrochim. Acta, 14, 1259 (1969).

33. E. J. Bottani and J. M. D. Tascón, Adsorption by Carbons: Novel Carbon Adsorbents, Elsevier Science (2011).

34. X. Gao, A. Omosebi, J. Landon, and K. Liu, J. Electrochem. Soc., 161, E159 (2014).

35. A. J. Bard and L. R. Faulkner, Electrochemical Methods: Fundamentals and Applications, Wiley (2000).

36. X. Gao, S. Porada, A. Omosebi, K. L. Liu, P. M. Biesheuvel, and J. Landon, Water Res., 92, 275 (2016)

37. K. Bourikas, C. Kordulis, and A. Lycourghiotis, J. Colloid Interface Sci., 296, 389 (2006).

38. M. Morbidelli, A. Gavriilidis, and A. Varma, Catalyst Design: Optimal Distribution of Catalyst in Pellets, Reactors, and Membranes, Cambridge University Press (2005).

39. M. A. Montes-Morán, D. Suárez, J. A. Menéndez, and E. Fuente, Carbon, 42, 1219 (2004).

40. Z. Ogumi, Z. Takehara, and S. Yoshizawa, J. Electrochem. Soc., 131, 769 (1984).

41. C. Song and J. Zhang, in PEM Fuel Cell Electrocatalysts and Catalyst Layers, J. Zhang, Editor, p. 89, Springer London (2008).

42. A. J. Bard, R. Parsons, and J. Jordan, Standard Potentials in Aqueous Solution, Taylor \& Francis (1985).

43. J. E. Dykstra, R. Zhao, P. M. Biesheuvel, and A. van der Wal, Water Res., 88, 358 (2016).

44. J. Yang, L. Zou, and N. R. Choudhury, Electrochim. Acta, 91, 11 (2013)

45. Y. Zuo, S. Cheng, and B. E. Logan, Environ. Sci. Technol., 42, 6967 (2008). 